\title{
Withholding Tragic Knowledge May Lead to a Tragic Death: A Palliative Care Perspective: Reply
}

\author{
Megha Suri $\cdot$ Martin McKneally $\cdot$ Karen Devon
}

Published online: 27 August 2014

(C) Société Internationale de Chirurgie 2014

We thank Dr. Ying [1] for her important additions to the discourse on truth-telling and the maintenance of hope. We agree that encouraging unrealistic expectations is inconsistent with beneficence and may lead to harmful treatment decisions. Her examples illustrate how maintaining hope at the expense of realistic expectations can be misleading and harmful if unmodulated by wisdom and care. We believe with her that hope, administered by ear, can bring comfort without inflicting false expectations in the setting of a poor prognosis.

Since the half-life of what we accept as objective truth is limited [2], moral absolutism has been largely rejected in favor of a relational model of care and shared decision making. Attention to the subjective versions of truth brings us closer to that model of patient- and family-centered care.

In her thoughtful review of the ethical aspects of truthtelling [3], palliative care physician Michelle Gold advises that "insensitivity to the cultural norms or personal preferences of a patient can result in the provision of information to someone who is not willing or ready to hear it

M. Suri · M. McKneally $\cdot$ K. Devon $(\square)$

Department of Surgery, University of Toronto, Toronto, ON, Canada

e-mail: karen.devon@utoronto.ca

M. McKneally $\cdot$ K. Devon

Joint Centre for Bioethics, University of Toronto, Toronto, ON,

Canada

\section{McKneally}

Division of Thoracic Surgery, Toronto General Hospital,

University Health Network, Toronto, ON, Canada

K. Devon

Division of General Surgery, Women's College Hospital and

University Health Network, Toronto, ON, Canada and, thus, be a source of distress. The goal of truth telling in medicine is to achieve therapeutic efficacy. The amount of information provided to an individual should be tailored to their specific needs and might change with time. Patients maintain their autonomy in this way, and choose how much 'truth' they wish to hear. The physician does not compromise his/her commitment to honesty, and cultural or personal differences can be respected." Gold quotes Robert Brault: "Today I bent the truth to be kind, and I have no regret, for I am far surer of what is kind than I am of what is true."

Surgical curricula are beginning to change in the direction suggested by Ying, as ethics education is emerging as an important part of training and assessment. We encourage surgeons to collaborate with palliative care teams in end of life care, in order to re-direct hope toward successful ordering of emotional and financial affairs, a tranquil death, and an inspiring legacy.

\section{References}

1. Ying I (2014) Withholding tragic knowledge may lead to a tragic death: a palliative care perspective. World J Surg. doi:10.1007/ s00268-014-2676-y

2. Suri M, McKneally M, Devon K (2014) Tragic knowledge: truth telling and the maintenance of hope in surgery. World J Surg 38:1626-1630. doi:10.1007/s00268-014-2566-3

3. Gold M (2004) Is honesty always the best policy? Ethical aspects of truth telling. Intern Med J 34:578-580 